\title{
CERKEV ADVENTISTOV SEDMEGA DNE V SRBIJI
}

\author{
Zorica KubUrić \\ Filozofska fakulteta Univerze v Novem Sadu, Novi Sad \\ zoricakuburic@gmail.com
}

Adventisti imajo zelo specifičen sistem verovanja s sedemindvajsetimi členi vere, ki jih mora vsak vernik preučiti skupaj z duhovnikom, sam ali v skupini, preden se zaobljubi Bogu, preden je krščen in vključen v cerkev. Verovanja Cerkve adventistov sedmega dne (ustanovljene leta $1863 \mathrm{v}$ ZDA) so predstavljena $\mathrm{v}$ knjigi Verovanje adventistov sedmega dne (Bacchiocchi et al. 1994). Emilio Knechtle meni, da adventisti ne opredeljujejo in predpisujejo posebnega Creda, posebne veroizpovedi, niti seveda ne verujejo kar koli, temveč upoštevajo kot temelj svoje vere Sveto pismo v celoti (Knechtle 1980). Kljub temu pa je vprašanje »Kdo so adventisti sedmega dne in kaj verujejo? « zahtevalo neko selekcijo na tem temelju. Knechtle je razporedil adventistične nauke v tri skupine. Prva skupina temeljnih verovanj je skupna vsem evangeljskim protestantom in vključuje $53 \%$ členov vere. Drugo skupino tvori $33 \%$ členov vere, ki jih različne konservativne krščanske cerkve različno interpretirajo. Adventisti verujejo, da se vsak človek sam odloči, ali bo sprejel Kristusa ali ne, kar pomeni, da ne verujejo v predestinacijo; verujejo, da je dekalog stalno vodilo in merilo za življenje vseh ljudi in vseh ljudstev in da ga zato ne smemo niti opuščati niti spreminjati; obred krsta izvajajo $\mathrm{z}$ enkratno potopitvijo $\mathrm{v}$ vodo in ne priznavajo niti škropljenja $\mathrm{z}$ vodo niti trikratnega potapljanja; verujejo, da je bil človek ustvarjen tako, da bi lahko postal nesmrten, če bi prestal preizkušnjo; grešniki bodo zaradi svojih zlih del na koncu uničeni v gorečem jezeru, se pravi da adventisti ne verujejo v večni pekel, ampak v popolno izginotje greha; veru- 
jejo, da spoštovanja sedmega dne - sobote - obvezuje vse ljudi (od tod njihov naziv); verujejo, da je Bog svet ustvaril dobesedno v šestih dneh in ne z evolucijo; sodijo, da morata biti cerkev in država ločeni; vzdržujejo se alkohola, tobaka, mamil in hrane, ki je po Bibliji nečista. Tretja skupina naukov obsega $14 \%$, je specifična za adventista in se nanaša na eshatološka vprašanja; prav tem dajejo v svojem nauku poseben poudarek. (Knechtle 1980; Knechtle in Sohlman 1981)

Adventisti verujejo, da je Sveto pismo Stare in Nove zaveze zapisana Božja beseda, posredovana $z$ božjo inspiracijo svetih božjih ljudi (Bacchiocchi et al. 1994). Dar prerokovanja je bil ob začetkih adventistične skupnosti najpomembnejši božji dar, saj so zgradili svojo identiteto na verovanju v preroški dar Ellen White (1827-1915) (Kuburić 2006). Biblijsko vrstico iz Razodetja so kasneje interpretirali tako, da so identiteto adventistične skupnosti povezali s »cerkvijo preostalih«: »Zmaj pa se je razjezil nad ženo in se bojeval proti preostalim iz njenega rodu, proti tistim, ki se ravnajo po Božjih zapovedih in imajo Jezusovo pričevanje.« (Raz 12,17) Tako pričevanje (potrdilo/certifikat) naj bi bilo prerokovanje Ellen White.

$\mathrm{V}$ njihovem verskem sistemu je pomemben poudarek na obnašanju vernikov, na adventističnem way of life. Verujejo, da je posameznik tempelj, v katerem živi Sveti duh, zato mora skrbeti za zdrave življenjske navade, da bi ohranil nadzorni center svojega telesa, duha [angl. mind], ki je prebivališče, dom Kristusovega Duha. Adventisti tako že sto let poudarjajo pomen zdravih življenjskih navad. Ta poudarek na skrbi za zdravo življenje očitno prinaša tudi posvetne koristi: najnovejše raziskave naj bi ugotavljale, da so adventisti v vsej populaciji najmanj prizadeti od vseh razširjenih bolezni (Walton, Walton in Scharffenberg 1981; Nieman in Stanton 1988; Kuburić 2019). National Geographic na primer piše (november 2015), da so zaradi svojega življenjskega stila zgled dolgoživosti. Zaradi vpliva, ki ga ima način življenja na duhovno izkušnjo, postavlja adventistična cerkvena organizacija kot minimalno zahtevo, da nekdo postane njen član, vrsto življenjskih pravil, ki jih je treba spoštovati. Ta pravila vključujejo abstinenco od alkohola, tobaka, kemičnih sredstev, ki vplivajo na možgane in duha, nečiste hrane, kar vse naj 
bi dokazovalo povečevanje krščanske izkušnje pri oblikovanju in uporabi prostega časa. (Kuburić 2014) Adventisti verjamejo, da je zdravstvena reforma desna roka evangelija. [...]

$Z$ vidika verskih skupnosti, ki imajo za poslanstvo, da oznanjajo evangelij vsem ljudstvom, je proces konverzije, spreobračanja, nekaj legitimnega. Ker pa konverzija pomeni opustitev starega sistema in izbiro novih ciljev, to ne more pustiti ravnodušnih skupnosti, ki v tem procesu izgubljajo. Krščanstvo je zgodovinsko zraslo iz razmerja med svobodo, da se izbere Kristusov nauk, in pripravljenostjo, da se ostane v tako izbrani cerkvi. V svojem poizkusu znanstvene raziskave rasti adventistične cerkve se bom osredotočila na empirično raziskavo konverzij v Srbiji, v obdobju enega stoletja, odkar v Srbiji obstoje in misijonirajo protestantske cerkve. Misija je za take cerkve zadeva njihovega zemeljskega preživetja in ne le onstranskega odrešenja.

Procesi konverzije pritegujejo pozornost tako političnih in cerkvenih struktur kot znanstvenikov. V svojem bistvu je konverzija notranja transformacija in sprememba usmeritve. Sprememba usmerjenosti mišljenja in delovanja se običajno začne s srečanjem nekoga, ki išče, z nekom, ki pozna (odgovor). Duhovne skupnosti se rodijo iz interakcije procesov pričevanja. O tem sem pisala v članku Spreobrnitev v religijo, ki ti spregovori (2009).

Protestantizem je prišel v Srbijo iz Evrope, toda v Srbiji je dobil neke srbske značilnosti. Protestantov se je Srbiji oprijel izraz »novoverci« že od takrat, ko so v 19. stoletju nazarenci začeli preobračati pravoslavne Srbe v »novo vero«.

Po stotih letih misijonskega dela je adventistična cerkev na ozemlju Srbije najmočnejša protestantska skupnost med tistimi, ki niso vezane na neko manjšinsko narodnostno osnovo [kot na primer evangeličanski Slovaki]. Po ljudskem štetju 2002 se skoraj 20.000 prebivalcev izreka za pripadnost neki varianti adventizma. Glavna struja adventizma, ki jo predstavljajo sledilci Ellen White, je versko gibanje, ki temelji na misijonarski dejavnosti.

Branko Bjelajac piše o začetkih adventizma v Beogradu s prihodom diplomanta misijonarske šole v Fridensauu (Nemčija) Maxa Ludwiga 
leta 1909 v Beograd. Uradno je bila prva adventistična skupina ustanovljena 12. decembra 1909. Dnevnik Politika je sicer v svojem članku o adventistih 12. 9. 1923 kot začetek delovanja adventistov v Kraljevini Srbiji zabeležil letnico 1905. Leta 1911 je beograjski pravoslavni pop Ljubomir Mitrović po naročilu svojih cerkvenih oblasti prisostvoval ciklusu adventističnih srečanj, zapisal svoje vtise in jih objavil v knjižici z naslovom Religiozni vandrovci. Narejen je bil seznam tistih, ki so bili pripravljeni na konverzijo, in tistih, ki so ji izrecno nasprotovali. (Bjelajac 2003)

Adventisti so postali uradno priznana verska skupnost z odlokom ministra za verske zadeve 30. septembra 1922, s čimer jim je bila dovoljena svoboda opravljanja verskih dejavnosti.

Rast adventistične cerkve je bila opazna. Leta 1923 je jugoslovanska Zveza adventistov štela 26 cerkva in okrog 500 vernikov. Toda nova vlada $\mathrm{z}$ novim ministrom za verske zadeve je 5. maja 1924 delovanje adventistov in nazarencev prepovedala. Razlog za tako stališče vlade in tradicionalnih cerkva je bil po Bjelajcu verjetno v statistiki: leta 1926 je bilo adventističnih vernikov 1.093 in čez dve leti že 1.728. Leta 1929 naj bi bilo v Jugoslaviji več kot 1.600 adventistov, zbranih v 84 krajevnih cerkvah.

Ob koncu 20. stoletja je bilo v Srbiji okrog 6.600 vernikov, $3.081 \mathrm{v}$ Vojvodini in $3.077 \mathrm{v}$ preostali Srbiji. Taka porazdelitev ostaja vse do danes, ko naj bi bilo članov adventistične cerkve že več kot 10.000 (skupaj s člani njihovih družin je verjetno število štirikrat večje). (Bjelajac 2010, 123, 135)

Razvoj adventizma v Srbiji v zadnjem stoletju lahko vidimo kot tipičen primer razširjanja nove religije v novem okolju. Samo v beograjski osrednji adventistični cerkvi je bilo v tem času krščenih 3.500 vernikov. Cerkvene knjige jih sicer ne beležijo ustrezno: zaradi zaščite zasebnosti vernikov ne navajajo vseh, ki so se zaobljubili Bogu proti volji svojih družin, sorodnikov ali prijateljev; razlog za nebeležnje je tudi zaščita vernikov pred državnimi ustanovami, saj vztrajajo, da je religioznost zasebna zadeva vsakega posameznika. Kot osrednja katedralna cerkev je imela vedno dovolj članov za svoj obstoj in delovanje ter dajala ton tudi drugim cerkvam. V empirični analizi se bom osredotočila na ra- 
zvoj adventizma v Zemunu, bistveno manjši občini, kjer lažje spremljamo spremembe $v$ daljšem obdobju.

\section{Cerkvena občina v Zemunu}

Začetki cerkve adventistov sedmega dne in njene misijonske dejavnosti v Zemunu ${ }^{1}$ segajo v leto 1933 . V cerkveni knjigi je zabeleženo 621 vernikov, od tega 68 \% žensk in $32 \%$ moških. Od začetkov do danes se je izmenjalo mnogo pridigarjev, v skladu $\mathrm{z}$ naukom in prakso adventistične cerkve, da vsakih nekaj let zamenja pridigarja. Od začetkov do leta 2004 je bilo tako 18 pridigarjev (in trije asistenti), ki so se menjali vsake 4 leta. Premeščanje pridigarjev spremljajo spremembe na ravni regije vsake 3 leta in volitve vodstvenega odbora cerkve v regiji vsakih 5 let. Južna regija, kamor spada zemunska občina, je imela tako do zdaj 14 predsednikov. Življenje in delo pridigarjev je tako odvisno od vodstvenih struktur ter od pridigarjeve osebnosti ter zmožnosti, da izpolnjuje zahteve svojega poklica, dobro sodeluje $\mathrm{z}$ vodilnimi cerkvenimi organi $\mathrm{v}$ regiji in Zvezi, $\mathrm{z}$ verniki in socialnim okoljem, $\mathrm{v}$ katerem misijonsko deluje. Na čelu krajevne cerkve je cerkveni odbor s predsednikom, volijo ga vsako leto, kar omogoča, da so člani zamenjani ali ponovno izvoljeni. Vpogled v življenje in delovanje različnih krajevnih cerkva pokaže, da je najbolj nestabilna vodstvena struktura na ravni cerkvene občine, saj je na novo postavljena vsako leto s strani starih vernikov in tistih, ki so bili na novo pokristjanjeni. Profesionalni cerkveni delavci zasedajo v cerkvi tri vrste položajev: položaj škofa ali duhovnika v občini, ki je neposredno povezan s krajem in verniki (ter odvisen od njih); položaj administratorja, ki ne opravlja obredov, njegov profesionalni položaj je stabilnejši in je redkeje zamenjan; položaj uradnikov Zveze, ki se reorganizirajo le vsakih 5 let.

Širjenje adventizma na teh območjih je bilo sistematično. Vsako leto so bile organizirane javne kampanje pridiganja, imenovane evangeliza-

1 Del sledečega poglavja je bil že objavljen v Kuburić 2004. 
cija. Njihov cilj je bil seznanjati publiko z bližnjim Kristusovim prihodom in potmi za odrešitev samega sebe od greha in tega sveta od zla. Evangelizaciji so sledila predavanja in seminarji. Ti so poizkušali odgovarjati na razna vprašanja, povezana s prerokbami v Bibliji. Tisti, ki so vztrajali na predavanjih in seminarjih, so postali jedro skupine, ki se je pridružila cerkvi, in imeli so občutek, da so odkrili nekaj, kar so iskali vse življenje. V starejših časih so se novim vernikom pridružili izbrani dotedanji člani, ki so jih uvedli v življenje cerkve in jim dodelili različne naloge pri obredih in dobrodelnih dejavnostih. Vedno bolj pa se je uveljavljala druga pot - da so za skupino tistih, ki so najdlje vztrajali pri predavanjih in še naprej kazali interes za verske zadeve in način življenja, kot ga je zahteval adventistični verski sistem, ustanovili novo cerkev, ki so se ji pridružili najaktivnejši in skrbno izbrani starejši člani. Podala bom pregled obeh variant cerkvenega organiziranja v Zemunu.

Odkrite vizije, jasna obzorja, zavest o lastni vlogi in mestu na tem svetu v procesu odrešenja sveta v bližnjem času - vse to močno motivira vernika za reševanje tudi njegovih bližnjih/sorodnikov, da se jih $\mathrm{z}$ navdušenjem zbira, da pridejo in slišijo resnico. Resnica je močna in dovolj je, da se ji posameznik podredi in se z zaupanjem pridruži skupnosti. Kasnejši stalni stiki z verniki to zaupanje sicer demistificirajo, saj tudi sami niso svetniki, čeprav bi to hoteli biti. Po izvedenih raziskavah (Dudley 1992, 18 in Dudley 1999) povprečno vsak drugi vernik zapusti skupnost, največkrat mladi ljudje, ki hočejo biti svobodni pri izbiri svojega zakonskega partnerja, ali ker njihovo delo ne prenaša religioznega življenja, ali ker ne zmorejo doseči standardov pričakovanega obnašanja, ali ker so razočarani nad sabo ali drugimi verniki ... Tako se dogaja, da polovica navdušencev skupnost vernikov zapusti. Toda bili so vendarle obogateni z novim izkustvom, ki jih po obdobju življenja brez boga pogosto pripelje nazaj v cerkev, ko se upokojijo, po razvezi zakona ali po drugih izgubah, ko kljubovanje bogu zamre in se zgodi kesanje, ki jih privede k ponižnosti in predanosti, ki jo nihče ne more več zatreti. V Jezusovi pridigi o izgubljenem sinu in njegovem bratu sta opisana dva tipa vernikov. Brat, ki je vseskozi zvest domu, je nesrečen, ker oče z njim ravna enako kot $z$ bratom, ki je iskal srečo zunaj očetovega doma. Tisti, 
ki se vrnejo, so pogosto privilegirani, ker jih očetova ljubezen pripravi, da so zmožni odpuščanja. Kot med otroci v družini tudi med verniki v skupnosti lahko prihaja do ljubosumja in zavisti, ki otežuje odnose in medsebojno razumevanje. Verniki, ki so prva generacija spreobrnjencev, in verniki, ki so že rojeni $v$ družinah $z$ adventistično tradicijo, so pogosto razpeti med ljubeznijo in ljubosumnostjo, med sodelovanjem in tekmovanjem. Spreobrnjenci so velik zaklad: njihova nova duhovnost osveži vsako cerkev in jo naredi za rastočo družino; njihovo mesto je v vsaki cerkvi, ki bogati dinamiko svojega življenja. V cerkvenih knjigah imamo po zaslugi krajevnih duhovnikov zabeležene vse člane cerkve v zaporedju, kot so bili krščeni, tudi tiste, ki so odšli ali bili ekskomunicirani. Zabeleženi so datumi krsta, rojstva in sprejema. Če je bil član kasneje izključen, če je odšel ali umrl, njegovo ime ni izbrisano in podatki o njem ostajajo. Na osnovi teh podatkov, ki so jih zbrali v cerkvenih občinah, dobimo naslednjo sliko:

Med letoma 1933 in 1999 je bilo krščenih 621 vernikov. Od teh jih je bilo 73 kasneje izključenih (12 \% vseh krščenih). V začetku je bilo število izključenih večje, medtem ko so bili v zadnjem desetletju verniki redko ekskomunicirani, tudi če dalj časa niso več prišli blizu. Kot razloge za izključitev iz skupnosti zapisi največkrat navajajo kršenje zapovedi dekaloga ali splošno »nekrščansko življenje«:

- $\quad 34 \%$ nekrščansko življenje

- $\quad 27 \%$ kršenje 4 . zapovedi (nespoštovanje sobote)

- $11 \%$ kršenje zapovedi dekaloga brez navedbe katere

- 10 \% nespoštovanje krščanskih dogem

- $7 \%$ kršenje 7 . zapovedi [»Ne prešuštvuj!«]

- $5 \%$ pridružitev drugi verski skupnosti (Jehovove priče, baptisti)

- $3 \%$ na lastno zahtevo

- $2 \%$ alkoholizem

- $\quad 1 \%$ kršitev 6. zapovedi [»Ne ubijaj«!]

Po zapisih je bilo leta 1999 v Zemunu 164 adventistov; od tega jih je 7 kasneje odšlo v Avstralijo, 2 v ZDA, 2 v Anglijo in 1 v Nemčijo. 
Od leta 1950 do 1999 je bilo krščeno 370 vernikov, 71 pa jih je prišlo iz drugih adventističnih cerkva. V povprečju je torej zemunska skupnost vsako leto pridobila 9 novih vernikov, skupaj 441, istočasno je šlo drugam 218 vernikov, od teh 41 v tujino: največ, 15, v Avstralijo, 13 v Nemčijo, 6 v ZDA, 3 v Francijo, 2 v Anglijo, 1 v Bolgarijo. Lahko sklepamo, da je v tujino odšlo okrog 10 \% vernikov. Po podatkih Zveznega urada za statistiko je sicer delalo vsaj začasno v tujini okrog $6 \%$ prebivalcev ožje Srbije (iz Pomoravja na primer $14 \%$ ). Zanimivo bi bilo natančneje primerjati podatke o začasnem ali stalnem izseljevanju v tujino prebivalcev Srbije sploh in posebej adventistov, da bi ugotovili, ali je ta tip zahodnega krščanstva ena od poti (in spodbud) za odhajanje na zahod.

$\mathrm{Na}$ osnovi teh podatkov lahko sklepamo, da je cerkveno življenje dinamično in da je fluktuacija vernikov velika. Pritok novih vernikov je vsako leto večji od števila tistih, ki odidejo. Praviloma se v cerkve vključijo s krstom, nekaj pa jih sprejmejo na osnovi pričevanja vernikov ali na osnovi dokumenta, da je bil nekdo krščen v drugi adventistični cerkvi. Krajevno cerkev lahko zapustijo iz različnih razlogov, vendar cerkvena občina beleži vse vernike, dokler ti spoštujejo Božje in cerkvene zakone ter pravila in obiskujejo cerkev. Pridigarjem je bilo priporočeno, da ekskomunicirajo vernike, ki ne prihajajo več v cerkev (razen če so opravičeni zaradi bolezni in starosti), ter tiste, ki kršijo zapovedi ali načela, ki se jih drži cerkev.

Najmanj je bilo krščenih v letih 1958 in 1969 (po 1), največ pa v letih 1951 (20), 1963 (16) in 1994 (35), povprečno, kot rečeno, na leto 9; če primerjamo desetletja, je bila najuspešnejša dekada 1990-1999, čas jugoslovanske krize, ko je bilo v Zemunu krščeno skupaj 120 vernikov (povprečno v obravnavanih dekadah 74 ).

Zemunska občina je vključevala več vaških cerkva, od katerih pa je delujoča le še ena v Dobanovcih. V tej vaški občini je bilo v obdobju 1934-1999 zabeleženo 137 vernikov (od tega jih je bilo 40 izključenih, največ zaradi nespoštovanja sobote, nekrščanskega življenja, prepirov, alkoholizma, poroke z neadventistom). Po teh zabeležkah je bilo torej izključenih 30 \% članov in število tistih, ki so cerkev zapustili, je bilo večje od števila tistih, ki so ostali. V vaški cerkvi v Bečmenu je bilo v obdob- 
ju 1933-1988 krščenih 70 vernikov; leta 1988 je cerkev nehala delovati, verniki so prešli k občini v Dobanovcih; 49 se jih je v tem času preselilo drugam, dobra četrtina teh v tujino. Skupnost v Surčinu je začela $\mathrm{z}$ delom leta 1968 in prenehala obstajati leta 1989: od registriranih 24 vernikov so bili 4 izključeni, polovica pa jih je odšla v druge skupnosti.

Moderni način sprejemanja novih vernikov je, kot smo omenili, povezan $z$ ustanavljanjem nove cerkve. S predavanji in seminarji v najetih prostorih se poslušalci postopoma seznanijo s cerkvenimi nauki in iz skupine aktivnih se oblikuje nova cerkev, ki se ji pridruži jedro misijonarjev iz že obstoječe cerkve. Tako je bila leta 1991 formirana nova cerkev, ki je dobila ime po kinodvorani Kozara, kjer so bila organizirana predavanja in kasneje obredi. Od leta 1991 njihova cerkvena knjiga beleži skupaj 77 vernikov. Od tega je bilo 34 krščenih po javni evangelizaciji na Politehnični akademiji v Beogradu in še 30 leta 1999. Večina članov je bila novih, drugi so prišli iz že obstoječe občinske cerkve v Beogradu. Samo 4 so bili izključeni in 9 jih je odšlo drugam ali v tujino.

Zanimiv je vpogled v organizacijsko strukturo te cerkve, ki je nastala med največjo jugoslovansko krizo. Šlo je za ljudi, ki so dvomili v smisel življenja in bili pripravljeni menjati svojo identiteto ali druge stvari v svojem življenju. Sodeč po intervjujih, ki sem ji opravila $z$ verniki po obredih, je večina vernikov mladih, največ je študentov iz različnih območij Srbije in Črne gore, ki so v cerkvi našli svojo drugo družino, skupnost in duhovno usmeritev. Obredi in dejavnosti so sicer v stari zemunski cerkvi. Nekatere njihove življenjske zgodbe sem že objavila (Kuburić 2007 in 2009).

\section{Zaključek}

Cerkvene knjige zemunske adventistične občine imajo skupno zabeleženih 939 vernikov. Steber verskega življenja je občinska cerkev v Zemunu, ki je najštevilnejša in najstarejša. Okrog $70 \%$ so vernice in $30 \%$ verniki. V cerkvenih vodstvenih strukturah je slika obrnjena: vse vodstvene položaje zasedajo moški, čeprav so seveda v izvoljenih orga- 
nih tudi ženske. V občini lahko pridigar na svojem položaju ostane 4 leta; vsako leto krstijo ali sprejmejo v cerkev okrog 14 vernikov, od tega 9 v glavni cerkvi. Čim večja je cerkev, tem večje je tudi število novih vernikov. Poleg krsta pridigar skrbi tudi za druge obrede, kot so poroke in posvetitve otrok na zahtevo staršev. Redni obred, ki se izvaja ne glede na število vernikov, je Gospodova večerja štirikrat na leto, ob koncu vsakega četrtletja. Verniki prejmejo nekvašen kruh in nealkoholno vino, simbola Kristusovega telesa in krvi. Kvas in vino sta simbola greha, od katerega se verniki pri tem obredu očistijo.

Če vprašamo o vplivu adventistične cerkve na mlade v tej regiji, lahko opazimo vpliv na povečanje motivacije za dosego višje izobrazbe. Kljub temu pa nekateri posamezniki v religiji najdejo tudi drugačen smisel, ki jih postopoma odvrača od študija in tega, da si ustvarijo družino. Svojo nepripravljenost, da bi prevzeli odgovornost za družino in pridobivanje materialnih dobrin zanjo, opravičujejo s sklicevanjem na bližnji Kristusov prihod in nujno potrebo oznanjati evangelij ljudem zaradi njihovega odrešenja v večnosti.

Znamenja izteka časa, ki jih nakazuje Sveto pismo, pri vsaki generaciji vedno znova vzbujajo upanje in strah ter prispevajo k vrednostnemu sistemu, ki usmerja življenje na zemlji. Duh protestantske etike, o kateri je pisal Max Weber, dviguje izobrazbeno raven in standarde obnašanja pri tistih, ki jo sprejemajo. Ta duh je navzoč tudi na poteh, ki vernike usmerjajo v razvite dežele, kjer zavzeto izpolnjujejo svojo zemeljsko misijo z marljivim delom ter pridobivajo vsakdanji kruh zase, a tudi za cerkev, ki jo s tako pridobljenimi sredstvi podpirajo, še posebej cerkev svoje domovine.

\section{LITERATURA}

Bacchiocchi, Samuele [Bakioki, Samuele], in kolektiv avtorjev. 1994. Adventistički hrišćani veruju: biblijsko izlaganje 27 osnovnih doktrina. Beograd: Preporod.

Bjelajac, Branko. 2003. Protestantizam u Srbiji: prilozi za istoriju reformacijskog nasleđa u Srbiji 1. Beograd: Alfa i Omega.

---. 2010. Protestantizam u Srbiji: prilozi za istoriju reformacijskog nasleda u Srbiji 2. Beograd: Soteria. 
Dudley, Roger. 1992. »The Lost Generation." Adventist Review 129 (14): 18-20.

---. 1999. Why Our Teenagers Leave the Church. Maryland, MD: Review and Herald Publishing.

Knechtle, Emilio. 1980. Hristos našživot: trideset propovedi za evangelizaciju 1980/1981. Beograd: HAC.

Knechtle, Emilio, in Charles Sohlman. 1981. Spremni za Hristov slavni dolazak. Beograd: HAC.

Kuburić, Zorica. 2004. »Is Conversion Result of Church Missionary Work or Proselytism?« V Evangelisation, Conversion, Proselytism, ur. Dragan Todorović, 6774. Niš: JUNIR.

---. 2006. »Uloga žene u verskom pokretu«. Godišnjak Filozofskog fakulteta u Novom Sadu 31: 623-40.

---. 2007. Religija, porodica i mladi. Novi Sad: CEIR; Beograd: Čigoja štampa.

---. 2009. »Obraćenje u religiju koja ti progovori.«V Konverzija i kontekst: teorijski, metodološki i praktički pristupi religijskoj konverziji, ur. Zorica Kuburić in Srđan Sremac, 17-42. Novi Sad: CEIR.

---. 2014. The Self-Image of Adolescents in the Protestant Family: A Study of Seventh-Day Adventist Families in Predominantly Orthodox Serbia. Lewiston, NY: Edwin Mellen Press.

---. 2019. »Natural Medicine in the Form of New Religiosity«. V Different Forms of Religiosity and the Modern World, ur. Mirko Bagojević in Zlatko Matić, 7-21. Beograd: Institute of Social Sciences.

Nieman, David C., in Jewel H. Stanton. 1988. »The Adventist Lifestyle: A Better Way to Live." Vibrant Life 103: 14-18.

Walton, Lewis R., Jo Ellen Walton in John A. Scharffenberg. 1981. How You Can Live Six Extra Years: Health and Longevity Secrets of the Seventh-Day Adventists That Could Add Six Years or More to Your Life Span. Santa Barbara, CA: Woodbridge Press.

Prevedel in po dogovoru z avtorico mestoma skrajšal Marko Kerševan 